\title{
Joint effusion, anteroposterior stability, muscle strength and degree of patellofemoral osteoarthritis significantly impact outcome following revision $\mathrm{ACL}$ reconstruction
}

\author{
Kathleen Andrä1,2, Enes Kayaalp², Robert Prill', Lars Irlenbusch², Eckehard Liesaus², Tilo Trommer²,
} Peter Ullmann ${ }^{2}$ and Roland Becker ${ }^{1 *}$ (D)

\begin{abstract}
Purpose: Effusion, impaired muscle function and knee instability are considered as some of the most important factors effecting outcome following anterior cruciate ligament reconstruction (ACL-R) but the impact on revision ACL-R remains unclear. It was hypothesized that these factors will significantly worsen clinical outcome following revision ACL-R.

Methods: Seventy knees (13 female and 57 male) were followed retrospectively after revision ACL-R at a mean follow-up of $47.8 \pm 20.7$ months. Clinical examination was based on the International Knee Documentation Evaluation Form-2000 (IKDC), Tegner activity scale. Instrumented measurement of anterior tibial translation was performed using the Rolimeter ${ }^{\oplus}$ (DJO Global, Freiburg, Germany). Bilateral circumference of the thigh was measured 10 and $20 \mathrm{~cm}$ proximal to the medial joint space. Cartilage was assessed according to Outerbridge classification during both primary and revision ACL-R.

Results: Tegner activity scale decreased significantly from $7.8 \pm 1.4$ points at primary ACL-R to $7 \pm 1.8$ points at revision $A C L-R$, and $5.8 \pm 1.7$ points at the time of follow up ( $p<0.001)$. Joint effusion $(r=-0.47, p \leq 0.01)$ and side to side differences in single leg hop test $(r=-0.48, p \leq 0.1)$ significantly correlated with inferior outcome. Cartilage lesions were found in $67 \%$ of the patients at the time of revision ACL-R compared to $38 \%$ at the time of primary ACL-R. According to the IKDC classification A was graded in three patients (4.3\%), B in 35 (50\%), C in 29 (41.4\%) and $\mathrm{D}$ in three (4.3\%). Joint effusion was measured in $35 \%$ of patients at the time of follow-up. Degeneration at the patellofemoral compartment of $\geq$ grad 2 was responsible for IKDC grade $C$ and $D(p=0.035)$. Instrumented anteroposterior site-to-site difference of $\geq 3 \mathrm{~mm}$ showed significant impact on clinical outcome $(p<0.019)$.
\end{abstract}

\footnotetext{
* Correspondence: Roland.Becker@mhb-fontane.de

This study was performed according to the Helsinki declaration. Ethical approval was given by the Ethical Committee at the University of Jena (5115-03/17) and all patients gave written consent.

${ }^{1}$ Center of Orthopaedics and Traumatology, University of Brandenburg, Medical School "Theodor Fontane", Hochstrasse 29, 14770 Brandenburg an der Havel, Germany

Full list of author information is available at the end of the article
}

\section{Springer Open}

(c) The Author(s). 2021 Open Access This article is licensed under a Creative Commons Attribution 4.0 International License, which permits use, sharing, adaptation, distribution and reproduction in any medium or format, as long as you give appropriate credit to the original author(s) and the source, provide a link to the Creative Commons licence, and indicate if changes were made. The images or other third party material in this article are included in the article's Creative Commons licence, unless indicated otherwise in a credit line to the material. If material is not included in the article's Creative Commons licence and your intended use is not permitted by statutory regulation or exceeds the permitted use, you will need to obtain permission directly from the copyright holder. To view a copy of this licence, visit http://creativecommons.org/licenses/by/4.0/. 
Conclusion: The study has shown that chronic effusion, quadriceps dysfunction, cartilage lesions especially at the patellofemoral compartment and side to side difference in anteroposterior stability significantly influences patient outcome after revision ACL-R. These factors require special attention when predicting patient's outcome.

Level of evidence: Level-IV, case-controlled study.

Keywords: Anterior cruciate ligament reconstruction, Revision, IKDC, Tegner activity scale, Effusion, Quadriceps, Instability

\section{Introduction}

Consensus criteria defined for successful outcome following anterior cruciate ligament reconstruction (ACLR) including effusion, laxity, muscle strength, functional performance and patients reported outcome [26]. However, it remains unclear whether the criteria developed for outcome assessment following primary ACL-R may be applicable for revision ACL-R.

Patients and surgery related factors were shown to influence the outcome following primary and revision ACL-R. For example, the incidence of osteoarthritis (OA) is increased after non-anatomical ACL-R in comparison with anatomical ACL-R (23.2\% vs $43.9 \%)$ after 10 years of follow up [31]. The type of graft does not seem to have an impact on knee stability following primary or revision ACL-R comparing the use of hamstring tendons [semitendinosus/gracilis (STG)], bone-patellar tendon-bone (BTB), or Achilles tendon allograft [1]. However, a meta-analysis of the literature showed better outcome when using autograft compared to allograft [13].

Numerous factors influence clinical and functional outcome following primary and revision ACL-R. While some authors reported no difference in muscle function and clinical outcome between primary and revision ACL-R others showed significant difference in muscle strength, patient related outcome measures and in frequency of return to sport $[6,23]$. Lefevre et al. found worse outcome following revision ACL-R based on clinical and functional assessment but a comparable rate of athletes returned to their previous sports activities [24]. Patient related factors are difficult to define for successful outcome after ACL-R. These factors are rather complex and influenced by interaction between muscle and knee function, concomitant knee pathologies, effusion, pain, limited range of motion but also by patient's motivation [4, 34, 36]. Effusion and inferior quadriceps force may reduce the likelihood of return to sport [9]. In contrast, age does not seem to show any impact on clinical outcome however, greater improvement according to KOOS was observed in younger patients after ACL-R [10, 21].

Effusion, muscle function and knee stability are proven as important factors for good clinical outcome following ACL-R, but the impact of these factors following revision ACL-R remain unclear.
It was hypothesized that impaired muscle function, effusion and anteroposterior instability will deteriorate clinical outcome following revision ACL-R.

\section{Material and methods}

The study was approved by the Ethical committee of the University of Jena, Germany (5115-03/17).

Revision ACL-R was performed in 154 patients at the Sports Clinic Erfurt between 2010 and 2015 after failed isolated ACL-R. Four strand STG was used for primary ACL- $\mathrm{R}$ in all patients. Revision ACL-R was performed using either STG of the contralateral side or BPTB grafts of the ipsilateral knee. Patients who received single stage isolated revision ACL-R with or without partial meniscus resection were included in the current study. Exclusion criteria were two stage revision surgery, additional surgery except revision ACL-R, concomitant ligament injuries and additional cartilage repair procedures. Seventy knees of seventy patients (13 female and 57 male) out of the 154 patients fulfilled the requirements and were followed retrospectively by an independent examiner who was not involved in patient treatment. The mean follow-up time was $47.8 \pm 20.7$ months (range, 15 to 84 months) after revision ACL-R. Contralateral STG was used in eleven patients and BTB in 59 patients. Mean age and BMI were $33 \pm 9$ years and $27 \pm 5 \mathrm{~kg} / \mathrm{m}^{2}$, respectively at the time of follow-up.

Clinical examination was based on the International Knee Documentation Evaluation Form-2000 (IKDC), and Tegner activity scale at the time of follow up (t3) $[19,39]$. Tegner activity scale was also recorded prospectively prior to primary (t1) and revision ACL-R (t2).

Cartilage staging according to the Outerbridge classification was recorded during primary and revision ACL-R for all three compartments separately [33].

Instrumented measurement was performed for evaluating the anterior tibial translation using the Rolimeter ${ }^{\circ}$ (DJO Global, Freiburg) [12]. The circumference of the thigh was measured bilaterally $10 \mathrm{~cm}$ and $20 \mathrm{~cm}$ proximal to the medial joint line.

\section{Statistical analysis}

Data were given as mean and standard deviation of the mean. Metric scaled numerical variables were analysed 
using the dependent t-test. For metric scaled data correlations were calculated with Pearson's correlation coefficient when normal distribution was proven with Shapiro Wilk test. Ordinal scaled data was correlated with Spearman rank correlation coefficient and for dichotomous data with exact Fisher's test.

Despite significance, correlation for linear models were estimated to be slightly clinically relevant in term of criterion-based validity when it is above 0.4 , relevant above 0.5 and strong when higher than 0.6. Factor analysis for estimation of combined loading on a factor seems not feasible in this sample size.

SPSS $\odot$ Statistics Version 27 (IBM Corporation, Armonk, USA) was used for Mac. P-value of $\leq 0.05$ was considered statistically significant.

\section{Results}

The Tegner activity scale decreased significantly from $7.8 \pm 1.4$ points at primary ACL-R (t1) to $7 \pm 1.8$ points at to revision ACL-R (t2), and to $5.8 \pm 1.7$ points at the time of follow up (t3) $(p<0.001)$. Forty-nine patients $(70 \%)$ reported at the time t2 a level of activity comparable to t1. This number dropped to 24 patients (34\%) at t3. None of the patients were able to maintain the level of activity when comparing between $\mathrm{t} 1$ and $\mathrm{t} 3$.

Patient which scored the Tegner activity scale lower at the time of primary ACL-R showed inferior results also at revision ACL- $\mathrm{R}$ ( $\mathrm{t} 1$ to $\mathrm{t} 2, \mathrm{r}_{\mathrm{s}}=0.68, p \leq 0.01$ ) but less relevant when considering the assessment between revision ACL-R and latest follow up ( $\mathrm{t} 2$ to $\mathrm{t} 3, \mathrm{r}_{\mathrm{s}}=0.40, p \leq 0.01$ ). Tegner activity scale at the time of follow up (t3) was highly valid for objective deficits, with slightly clinically relevant correlations for effusion $(r=-0.47, \mathrm{p} \leq 0.01)$ and side to side differences in single leg hop test $(r=-0.48$, $p \leq 0.1$ ). The circumference of the operated thighs in comparison to the contralateral one was reduced by $10 \pm 9$ $\mathrm{mm}$ and $17 \pm 12 \mathrm{~mm}$ at 10 and $20 \mathrm{~cm}$ proximal to the medial joint line respectively (Table 1 ). A significant correlation was found between muscle atrophy and results of a single leg hope test $(r=0.32, p \leq 0.03)$.

Minor correlation was found between the Pivotshift test and the Tegner activity scale $(r=-0.29, p \leq 0.05)$. Instrumented AP site-to-site difference of $\geq 3 \mathrm{~mm}$ showed significant impact on the Tegner activity scale $(p \leq 0.019)$.

IKDC was graded as A in three patients (4.3\%), B in 35 (50\%), C in 29 (41.4\%) and D in three (4.3\%). Normal or nearly normal knee function was in $54.3 \%$ of the patients at the time of follow-up. All parameters of the IKDC are given in detail in Table 2 .

Cartilage lesions were found in $67 \%$ of all patients at the time of revision ACL-R in comparison to $38 \%$ at the time of primary ACL-R (Table 3). Lesions at the medial femoral condyle of grad II to IV were apparent following primary and revision ACL-R in 19 (27\%) and 42 (60\%) patients, respectively. The lateral compartment showed grade II to IV lesions in $2(3 \%)$ patients at the time of primary ACL-R and increased to $6(8,5 \%)$ patients at the time of revision. The number of patients with patellofemoral osteoarthritis of grade II to IV increased from 6 (8.6\%) to $20(28 \%)$ patients. Patellofemoral osteoarthritis of $\geq \operatorname{grad}$ II was a significant factor for IKDC Grade C and $\mathrm{D}(p=0.024)$. Partial medial meniscus resection showed an impact on side-to-side difference in one leg hop test $(p \leq 0.001)$, effusion $(p \leq 0.014)$ and pivot shift $(p \leq 0.031)$, while lateral meniscus resection showed an impact on the pivot shift test only $(p \leq 0.017)$.

\section{Discussion}

The most important finding of the study was that joint effusion, AP stability and site-to-site difference in one leg hop test affected significantly the clinical outcome following revision ACL-R. Joint effusion was found in $35 \%$ of patients at the time of follow-up. Persistent knee effusion after ACL-R surgery has been reported previously [38]. Effusion significantly reduces quadriceps muscle activation and muscle strength $[25,29]$. Thus, it is not surprising that effusion belongs to one of the six important outcome measures for ACL surgery beside giving way, muscle strength, activity and participation and return to sport [26]. According to one-leg-hop-test, $41 \%$ of the patients showed nearly normal side to side muscle strength. Even though high percentage of patients presented side-to-side differences in one-leg-hoptest however, no impact on IKDC was found in the current study. Although there was no impact on IKDC, hop-index between the healthy and injured sides are reliable measure for quadriceps muscle function [29]. Significant correlation between quadriceps muscle atrophy and hop-index was found in the current study. The operated side commonly presents an impaired maximal quadriceps muscle strength achieving up to $88 \%$ of the none operated, contralateral side $[8,28,30,37]$. It was shown that higher quadriceps strength asymmetry is

Table 1 Side to side difference of the thigh at $10 \mathrm{~cm}$ and $20 \mathrm{~cm}$ above the medial joint space. Reduction in thigh circumference was seen on the operated side

\begin{tabular}{lll}
\hline Side to side difference of thigh circumference & $\mathbf{1 0} \mathbf{c m}$ above the media space & $\mathbf{2 0} \mathbf{c m}$ above the medial space \\
Side to side difference $\mathbf{1 0 - 2 0 ~} \mathbf{m m}$ & $68.2 \%$ & $54.5 \%$ \\
Side to side difference $>\mathbf{2 0} \mathbf{~} \mathrm{m}$ & $3 \%$ & $25.8 \%$ \\
\hline
\end{tabular}


Table 2 Number of patients and percentage of each parameter according to IKDC

\begin{tabular}{|c|c|c|c|c|}
\hline Parameter & Normal (A) & Nearly normal (B) & Abnormal C & Severly abnormal (D) \\
\hline Effusion & $46(65.7 \%)$ & $20(28.6 \%)$ & $4(5.7 \%)$ & 0 \\
\hline Donor site morbidity & $28(40 \%)$ & $36(51.4 \%)$ & $6(8.6 \%)$ & 0 \\
\hline Crepitus patellofemoral & $22(31.4 \%)$ & 0 & $46(68.6 \%)$ & $2(2.8 \%)$ \\
\hline Crepitus medial compartment & $56(80 \%)$ & 0 & $13(18.6 \%)$ & $1(1.4 \%)$ \\
\hline Crepitus lateral compartment & $63(90 \%)$ & 0 & $7(10 \%)$ & 0 \\
\hline Lack of flexion & 37 (52.9\%) & $31(44.2 \%)$ & $2(2.8 \%)$ & 0 \\
\hline Lack of extension & $34(48.6 \%)$ & $20(28.6 \%)$ & $15(21.4 \%)$ & $1(1.4 \%)$ \\
\hline Lateral joint opening & $48(68.6 \%)$ & $21(30 \%)$ & $1(1.4 \%)$ & 0 \\
\hline Medial joint opening & $57(81.4 \%)$ & $10(14.3 \%)$ & $3(4.3 \%)$ & 0 \\
\hline Lachman test ( $25^{\circ}$ flexion) & $15(21.5 \%)$ & $47(67.2 \%)$ & $7(10 \%)$ & $1(1.4 \%)$ \\
\hline Anterior drawer ( $90^{\circ}$ flexion) & $16(22.9 \%)$ & $48(68.6 \%)$ & $5(7.1 \%)$ & $1(1.4 \%)$ \\
\hline Ligament evaluation (instrumented side to side difference) & $15(21.4 \%)$ & $48(68.6 \%)$ & $6(8.6 \%)$ & $1(1.4 \%)$ \\
\hline Posterior drawer ( $90^{\circ}$ flexion) & $69(98.6 \%)$ & 0 & 0 & $1(1.4 \%)$ \\
\hline Pivot-shift test & $51(72.9 \%)$ & $10(14.3 \%)$ & $7(10 \%)$ & $2(2.8 \%)$ \\
\hline External rotation $\left(30^{\circ}\right.$ flexion $)$ & $41(58.6 \%)$ & $26(37.1 \%)$ & $3(4.3 \%)$ & 0 \\
\hline External rotation $\left(90^{\circ}\right.$ flexion $)$ & $64(91.4 \%)$ & $3(4.3 \%)$ & $3(4.3 \%)$ & 0 \\
\hline One leg hop test & $29(41.4 \%)$ & $20(28.6 \%)$ & $6(8.6 \%)$ & $15(21.4 \%)$ \\
\hline
\end{tabular}

more likely in patients with lower quadriceps strength [29]. This might be one of the reasons that only $20 \%$ of the patients showed symmetrical knee function 6 months following ACL-R [15]. The difference in thigh circumference may progress after revision ACL-R [41].

Reduction in voluntary quadriceps muscle activation has been reported after primary ACL-R $[18,37]$. The reduction of voluntary activation can be improved by ACL-R but remains bilaterally inferior to healthy subjects. Revision ACL-R does not seem to show an additional effect on quadriceps muscle dysfunction [23]. However, quadriceps dysfunction is known as a risk factor for knee osteoarthritis [3, 11].

Knee stability measured by ap translation and Pivotshift-test showed significant impact on clinical and functional outcome after revision ACL-R. Patients with persistent anteroposterior instability or positive Pivotshift-test showed lower scores in the current study based on the Tegner activity scale. None of the patients of the current study received surgery at the periphery of the knee but there is an increasing awareness nowadays for looking at rotation instability prior to revision surgery [20]. Studies have shown that lateral tenodesis or anterolateral ligament reconstruction improve knee stability after revision surgery [7, 13, 35].

Cartilage degeneration is significantly advanced after ACL surgery than in the aged matched healthy population and showed impact on clinical outcome. Increase in cartilage degeneration was observed in all three compartments of the current study. Degeneration in the patellofemoral compartment showed most significant impact on clinical outcome. In contrast, it was reported that the status of articular cartilage makes the most significant impact on successful revision ACL-R after a follow-up time of 5-9 years [32]. Patients' follow-up of the current study was 4 years, and further progression of OA remains unknown.

Increase in AP instability was found after revision ACL-R. Interestingly, the study by Cristiani et al. did not find any difference in AP stability after primary and revision ACL-R, but lower clinical outcome was observed after revision surgery [8]. Activity of daily life, symptoms

Table 3 Assessment of cartilage damage during primary and revision ACL-R according to the classification by Outerbridge

\begin{tabular}{|c|c|c|c|c|c|c|c|c|c|c|}
\hline \multirow{2}{*}{$\begin{array}{l}\text { Outerbridge-classification } \\
\text { ACL surgery }\end{array}$} & \multicolumn{2}{|c|}{ Patellofemoral } & \multicolumn{2}{|c|}{ Medial tibia } & \multicolumn{2}{|c|}{ Lateral tibia } & \multicolumn{2}{|c|}{ Medial femur } & \multicolumn{2}{|c|}{ Lateral femur } \\
\hline & primary & revision & primary & revision & primary & revision & primary & revision & primary & revision \\
\hline Grade 0 & 65 & 51 & 71 & 66 & 71 & 69 & 51 & 29 & 69 & 65 \\
\hline Grade 1 & 0 & 2 & 0 & 0 & 0 & 0 & 1 & 0 & 0 & 0 \\
\hline Grade 2 & 4 & 6 & 0 & 1 & 0 & 1 & 12 & 18 & 2 & 1 \\
\hline Grade 3 & 2 & 10 & 0 & 3 & 0 & 1 & 7 & 14 & 0 & 3 \\
\hline Grade 4 & 0 & 2 & 0 & 1 & 0 & 0 & 0 & 10 & 0 & 2 \\
\hline
\end{tabular}


and pain according to KOOS showed inferior results following revision ACL-R. On the contrary, increase in side-to-side difference in AP stability was significantly associated with worse outcome according to Tegner activity scale.

The incidence of OA following ACL- $\mathrm{R}$ is $12 \%$ based on an insurance database after 4 years of follow-up [5]. The odds ratio of developing OA in patient over the age of 35 years was 2.44. There is a significant progression of OA considering the incidence of 43\% 10 years after ACL-R [22]. Radiographic knee OA of grade $\geq 2$ was detected in $71 \%$ of patients at 10 to 15 years of follow-up time underlining the significant increase in the prevalence of OA with time [42]. In contrast, the incidence of $\mathrm{OA}$ in healthy subjects is $7.3 \%$ in woman and $6.2 \%$ in men at a mean age of $41.8 \pm 12.9$ years and significantly lower than in patients after ACL-R [16]. The incidence of OA after ACL-R is significantly higher than in healthy subjects. Additional damage of both cartilage and subchondral bone can be presumed after revision ACL-R. Other studies also showed worse outcome and a three to four times higher revision rate after revision ACL-R when compared to primary ACL-R [40]. The outcome based on Tegner activity scale was comparable to previous studies $[15,40]$. The Tegner activity scale decreased from 8 points prior to ACL-R to 7 points prior to revision ACL-R to 6 points at the time of follow-up considering the minimal detectable change of 1 [17]. Differences between the two groups can be presumed.

In contrast to the MARS group age did not show any impact on clinical and functional outcome [2]. One reason might be the lower median age of 26 yrs. in the cohort of the MARS-study in comparison to the mean age of $33 \mathrm{yrs}$. in the current study.

The study has certain limitations. First, the study was retrospectively designed. Patients received either STG from the contralateral side or BTB graft from the ipsilateral side. However, according to the MARSstudy no difference in clinical outcome was found between STG and BTB graft after revision ACL-R [27]. A meta-analysis of 32 studies showed that no difference exists between hamstring or BTB graft, but STG resulted in better IKDC knee scores [14]. The impact on quadriceps function remains unclear. In the current study, baseline data in terms of muscle function and IKDC were missing.

In conclusion, special attention needs to be paid to joint effusion and knee laxity in patients following revision ACL-R. Degeneration of the patellofemoral compartment might be treated more sustainable during revision surgery with appropriate cartilage procedures. The expectation in relation to patients age needs to be discussed when revision surgery is considered.

\section{Authors' contributions}

Data collection has been performed by Andrä, Irlenbusch, Liesaus, Ullmann and Trommer. The data were analysed and the manuscript written by Andrä, Becker, Prill and Kayaalp. Final correction of the manuscript was performed by all authors. The author(s) read and approved the final manuscript.

Funding

Open Access funding enabled and organized by Projekt DEAL.

\section{Competing interests}

The authors declare that they have no competing interests.

\section{Author details}

${ }^{1}$ Center of Orthopaedics and Traumatology, University of Brandenburg, Medical School "Theodor Fontane", Hochstrasse 29, 14770 Brandenburg an der Havel, Germany. ${ }^{2}$ Sports Clinic Erfurt, Erfurt, Germany. ${ }^{3}$ Department of Orthopedics and Traumatology, Istanbul Taksim Training and Research Hospital, Siraselviler Cad. 34433 Beyoglu, Istanbul, Turkey.

Received: 22 May 2021 Accepted: 12 July 2021

Published online: 26 August 2021

\section{References}

1. Ahn JH, Lee YS, Ha HC (2008) Comparison of revision surgery with primary anterior cruciate ligament reconstruction and outcome of revision surgery between different graft materials. Am J Sports Med 36(10):1889-1895. https://doi.org/10.1177/0363546508317124

2. Allen CR, Anderson AF, Cooper DE, DeBerardino TM, Dunn WR, Haas AK, Huston LJ, Lantz BBA, Mann B, Nwosu SK, Spindler KP, Stuart MJ, Wright RW, Albright JP, Amendola AN, Andrish JT, Annunziata CC, Arciero RA, Bach BR, Baker CL, Bartolozzi AR, Baumgarten KM, Bechler JR, Berg JH, Bernas GA, Brockmeier SF, Brophy RH, Bush-Joseph CA, Butler JB, Campbell JD, Carey JL, Carpenter JE, Cole BJ, Cooper JM, Cox CL, Creighton RA, Dahm DL, David TS, Flanigan DC, Frederick RW, Ganley TJ, Garofoli EA, Gatt CJ, Gecha SR, Giffin JR, Hame SL, Hannafin JA, Harner CD, Harris NL, Hechtman KS, Hershman EB, Hoellrich RG, Hosea TM, Johnson DC, Johnson TS, Jones MH, Kaeding CC, Kamath GV, Klootwyk TE, Levy BA, Ma CB, Maiers GP, Marx RG, Matava MJ, Mathien GM, McAllister DR, McCarty EC, McCormack RG, Miller BS, Nissen CW, O'Neill DF, Owens BD, Parker RD, Purnell ML, Ramappa AJ, Rauh MA, Rettig AC, Sekiya JK, Shea KG, Sherman OH, Slauterbeck JR, Smith MV, Spang JT, Svoboda SJ, Taft TN, Tenuta JJ, Tingstad EM, Vidal AF, Viskontas DG, White RA, Williams JS, Wolcott ML, Wolf BR, York JJ (2017) Surgical predictors of clinical outcomes after revision anterior cruciate ligament reconstruction. Am J Sports Med 45(11):2586-2594. https://doi. org/10.1177/0363546517712952

3. Becker R, Berth A, Nehring M, Awiszus F (2004) Neuromuscular quadriceps dysfunction prior to osteoarthritis of the knee. J Orthop Res 22(4):768-773. https://doi.org/10.1016/j.orthres.2003.11.004

4. Becker R, Karlsson J (2018) The role of muscle function after anterior cruciate ligament rupture and treatment. Knee Surg Sports Traumatol Arthrosc 26(2):355-357. https://doi.org/10.1007/s00167-018-4829-2

5. Bodkin SG, Werner BC, Slater LV, Hart JM (2020) Post-traumatic osteoarthritis diagnosed within 5 years following ACL reconstruction. Knee Surg Sports Traumatol Arthrosc 28(3):790-796. https://doi.org/10.1007/s00167-019-05461-y

6. Carolan D, King E, Richter C, Franklyn-Miller A, Moran R, Jackson M (2020) Differences in strength, patient-reported outcomes, and return-to-play rates between athletes with primary versus revision ACL reconstruction at 9 months after surgery. Orthop J Sports Med 8:2325967120950037

7. Colombet $P(2011)$ Knee laxity control in revision anterior cruciate ligament reconstruction versus anterior cruciate ligament reconstruction and lateral tenodesis: clinical assessment using computer-assisted navigation. Am J Sports Med 39(6):1248-1254. https://doi.org/10.1177/0363546510395462

8. Cristiani R, Mikkelsen C, Forssblad M, Engström B, Stålman A (2019) Only one patient out of five achieves symmetrical knee function 6 months after primary anterior cruciate ligament reconstruction. Knee Surg Sports Traumatol Arthrosc 27(11):3461-3470. https://doi.org/10.1007/s00167-019-05396-4

9. Czuppon S, Racette BA, Klein SE, Harris-Hayes M (2014) Variables associated with return to sport following anterior cruciate ligament reconstruction: a systematic review. Br J Sports Med 48(5):356-364. https://doi.org/10.1136/ bjsports-2012-091786 
10. Desai N, Björnsson H, Samuelsson K, Karlsson J, Forssblad M (2014) Outcomes after ACL reconstruction with focus on older patients: results from the Swedish National Anterior Cruciate Ligament Register. Knee Surg Sports Traumatol Arthrosc 22(2):379-386. https://doi.org/10.1007/s00167-013-2803-6

11. Fahrer H, Rentsch HU, Gerber NJ, Beyeler C, Hess CW, Grünig B (1988) Knee effusion and reflex inhibition of the quadriceps. A bar to effective retraining. J Bone Joint Surg Br 70(4):635-638. https://doi.org/10.1302/0301-620X.70B4.3403614

12. Ganko A, Engebretsen L, Ozer H (2000) The rolimeter: a new arthrometer compared with the KT-1000. Knee Surg Sports Traumatol Arthrosc 8(1):3639. https://doi.org/10.1007/s001670050008

13. Getgood AMJ, Bryant DM, Litchfield R, Heard M, McCormack RG, Rezansoff A, Peterson D, Bardana D, MacDonald PB, Verdonk PCM, Spalding T, Willits K, Birmingham T, Hewison C, Wanlin S, Firth A, Pinto R, Martindale A, O'Neill L, Jennings M, Daniluk M, Boyer D, Zomar M, Moon K, Pritchett R, Payne K, Fan B, Mohan B, Buchko GM, Hiemstra LA, Kerslake S, Tynedal J, Stranges G, Mcrae S, Gullett L, Brown H, Legary A, Longo A, Christian M, Ferguson C, Mohtadi N, Barber R, Chan D, Campbell C, Garven A, Pulsifer K, Mayer M, Simunovic N, Duong A, Robinson D, Levy D, Skelly M, Shanmugaraj A, Howells F, Tough M, Spalding T, Thompson P, Metcalfe A, Asplin L, Dube A, Clarkson L, Brown J, Bolsover A, Bradshaw C, Belgrove L, Millan F, Turner S, Verdugo S, Lowe J, Dunne D, McGowan K, Suddens CM, Declercq G, Vuylsteke K, Van Haver M (2020) Lateral extra-articular Tenodesis reduces failure of hamstring tendon autograft anterior cruciate ligament reconstruction: 2-year outcomes from the STABILITY study randomized clinical trial. Am J Sports Med 48(2):285-297. https://doi.org/10.1177/0363546519896333

14. Grassi A, Nitri M, Moulton SG, Marcheggiani Muccioli GM, Bondi A, Romagnoli M, Zaffagnini S (2017) Does the type of graft affect the outcome of revision anterior cruciate ligament reconstruction? A meta-analysis of 32 studies. Bone Joint J 99-B(6):714-723. https://doi.org/10.1302/0301-620X. 99B6.BJJ-2016-0929.R2

15. Grossman MG, ElAttrache NS, Shields CL, Glousman RE (2005) Revision anterior cruciate ligament reconstruction: three- to nine-year follow-up. Arthroscopy 21(4):418-423. https://doi.org/10.1016/j.arthro.2004.12.009

16. Grotle M, Hagen KB, Natvig B, Dahl FA, Kvien TK (2008) Obesity and osteoarthritis in knee, hip and/or hand: an epidemiological study in the general population with 10 years follow-up. BMC Musculoskelet Disord 9(1): 132. https://doi.org/10.1186/1471-2474-9-132

17. Harris JD, Brand JC, Cote MP, Faucett SC, Dhawan A (2017) Research pearls: the significance of statistics and perils of pooling. Part 1: clinical versus statistical significance. Arthroscopy 33(6):1102-1112. https://doi.org/10.1016/ j.arthro.2017.01.053

18. Hart JM, Turman KA, Diduch DR, Hart JA, Miller MD (2011) Quadriceps muscle activation and radiographic osteoarthritis following $A C L$ revision. Knee Surg Sports Traumatol Arthrosc 19(4):634-640. https://doi.org/10.1007/ s00167-010-1321-z

19. Hefti F, Müller W, Jakob RP, Stäubli HU (1993) Evaluation of knee ligament injuries with the IKDC form. Knee Surg Sports Traumatol Arthrosc 1(3-4): 226-234. https://doi.org/10.1007/BF01560215

20. Hughes JD, Rauer T, Gibbs CM, Musahl V (2019) Diagnosis and treatment of rotatory knee instability. J Exp Orthop 6(1):48. https://doi.org/10.1186/s4 0634-019-0217-1

21. Iorio R, lannotti F, Ponzo A, Proietti L, Redler A, Conteduca F, Ferretti A (2018) Anterior cruciate ligament reconstruction in patients older than fifty years: a comparison with a younger age group. Int Orthop 42(5):1043-1049. https://doi.org/10.1007/s00264-018-3860-8

22. Kessler MA, Behrend H, Henz S, Stutz G, Rukavina A, Kuster MS (2008) Function, osteoarthritis and activity after ACL-rupture: 11 years follow-up results of conservative versus reconstructive treatment. Knee Surg Sports Traumatol Arthrosc 16(5):442-448. https://doi.org/10.1007/s00167-008-0498-x

23. Kim DK, Park G, Kadir KBHMS, Kuo LT, Park WH (2018) Comparison of knee stability, strength deficits, and functional score in primary and revision anterior cruciate ligament reconstructed knees. Sci Rep 8(1):9186. https:// doi.org/10.1038/s41598-018-27595-8

24. Lefevre N, Klouche S, Mirouse G, Herman S, Gerometta A, Bohu Y (2017) Return to sport after primary and revision anterior cruciate ligament reconstruction: a prospective comparative study of 552 patients from the FAST cohort. Am J Sports Med 45(1):34-41. https://doi.org/10.1177/0363546516660075

25. Lindström M, Wredmark T, Wretling ML, Henriksson M, Felländer-Tsai L (2015) Post-operative bracing after ACL reconstruction has no effect on knee joint effusion. A prospective, randomized study. Knee 22(6):559-564. https://doi.org/10.1016/j.knee.2015.04.015
26. Lynch AD, Logerstedt DS, Grindem H, Eitzen I, Hicks GE, Axe MJ, Engebretsen L, Risberg MA, Snyder-Mackler L (2015) Consensus criteria for defining 'successful outcome' after ACL injury and reconstruction: a Delaware-Oslo ACL cohort investigation. Br J Sports Med 49(5):335-342. https://doi.org/10.1136/bjsports-2013-092299

27. MARS Group (2014) Effect of graft choice on the outcome of revision anterior cruciate ligament reconstruction in the multicenter ACL revision study (MARS) cohort. Am J Sports Med 42(10):2301-2310. https://doi.org/1 $0.1177 / 0363546514549005$

28. Ohji S, Aizawa J, Hirohata K, Ohmi T, Mitomo S, Jinno T, Koga H, Yagishita K (2021) Single-leg hop distance normalized to body height is associated with the return to sports after anterior cruciate ligament reconstruction. J Exp Orthop 8(1):26. https://doi.org/10.1186/s40634-021-00344-z

29. Palmieri-Smith RM, Lepley LK (2015) Quadriceps strength asymmetry after anterior cruciate ligament reconstruction alters knee joint biomechanics and functional performance at time of return to activity. Am J Sports Med 43(7):1662-1669. https://doi.org/10.1177/0363546515578252

30. Prill R, Michel S, Schulz R, Coriolano HA (2019) Body composition and strength parameters in elite judo athletes 5 years after anterior cruciate ligament reconstruction. Int J Sports Med 40(1):38-42. https:/doi.org/10.1055/a-0787-1420

31. Rothrauff BB, Jorge A, de Sa D, Kay J, Fu FH, Musahl V (2020) Anatomic ACL reconstruction reduces risk of post-traumatic osteoarthritis: a systematic review with minimum 10-year follow-up. Knee Surg Sports Traumatol Arthrosc 28(4):1072-1084. https://doi.org/10.1007/s00167-019-05665-2

32. Salmon $\sqcup$, Pinczewski LA, Russell VJ, Refshauge K (2006) Revision anterior cruciate ligament reconstruction with hamstring tendon autograft: 5- to 9-year follow-up. Am J Sports Med 34(10):1604-1614. https://doi.org/10.1177/0363546506288015

33. Slattery C, Kweon CY (2018) Classifications in brief: Outerbridge classification of chondral lesions. Clin Orthop Relat Res 476(10):2101-2104. https://doi. org/10.1007/s11999.0000000000000255

34. Sonesson S, Kvist J, Ardern C, Österberg A, Silbernagel KG (2017) Psychological factors are important to return to pre-injury sport activity after anterior cruciate ligament reconstruction: expect and motivate to satisfy. Knee Surg Sports Traumatol Arthrosc 25(5):1375-1384. https://doi.org/10.1007/s00167-016-4294-8

35. Thaunat M, Clowez G, Saithna A, Cavalier M, Choudja E, Vieira TD, Fayard JM, Sonnery-Cottet B (2017) Reoperation rates after combined anterior cruciate ligament and anterolateral ligament reconstruction: a series of 548 patients from the SANTI study group with a minimum follow-up of 2 years. Am J Sports Med 45(11):2569-2577. https://doi.org/10.1177/0363546517708982

36. Tran AA, Gatewood C, Harris AH, Thompson JA, Dragoo JL (2016) The effect of foot landing position on biomechanical risk factors associated with anterior cruciate ligament injury. J Exp Orthop 3(1):13. https://doi.org/10.11 86/s40634-016-0049-1

37. Urbach D, Nebelung W, Becker R, Awiszus F (2001) Effects of reconstruction of the anterior cruciate ligament on voluntary activation of quadriceps femoris a prospective twitch interpolation study. J Bone Joint Surg $\mathrm{Br} 83(8)$ : 1104-1110. https://doi.org/10.1302/0301-620X.83B8.0831104

38. Wellsandt E, Failla MJ, Axe MJ, Snyder-Mackler L (2018) Does anterior cruciate ligament reconstruction improve functional and radiographic outcomes over nonoperative management 5 years after injury? Am J Sports Med 46(9):2103-2112. https://doi.org/10.1177/0363546518782698

39. Wirth B, Meier N, Koch PP, Swanenburg J (2013) Development and evaluation of a German version of the Tegner activity scale for measuring outcome after anterior cruciate ligament injury. Sportverletz Sportschaden 27(1):21-27. https://doi.org/10.1055/s-0032-1330752

40. Wright RW, Gill CS, Chen L, Brophy RH, Matava MJ, Smith MV, Mall NA (2012) Outcome of revision anterior cruciate ligament reconstruction: a systematic review. J Bone Joint Surg Am 94(6):531-536. https://doi.org/10.2106/JBJS.K.00733

41. Ziegler CG, DePhillipo NN, Kennedy MI, Dekker TJ, Dornan GJ, LaPrade RF (2020) Beighton score, tibial slope, tibial subluxation, quadriceps circumference difference and family history are risk factors for acl graft failure: a retrospective comparison of primary and revision ACL reconstructions. Arthroscopy 37(1): 195-205. https://doi.org/10.1016/j.arthro.2020.08.031

42. Øiestad BE, Engebretsen L, Storheim K, Risberg MA (2009) Knee osteoarthritis after anterior cruciate ligament injury: a systematic review. Am J Sports Med 37(7):1434-1443. https://doi.org/10.1177/0363546509338827

\section{Publisher's Note}

Springer Nature remains neutral with regard to jurisdictional claims in published maps and institutional affiliations. 